\title{
EFFECT OF THE FABRIC REINFORCEMENT OF STRUCTURAL HOLES IN WOOD BASED PANELS
}

\author{
Nurdan Cetin Yerlikaya \\ Yalova University \\ TuRKEY \\ Abdurrahman Karaman \\ USAK UNIVERSITY \\ TuRKeY \\ (Received May 20I9)
}

\begin{abstract}
The objective of this study was to determine the effects of the glass fiber fabric reinforced holes in MDF, PB, OSB, and PL. The fabrics of $19 \mathrm{~mm}$ or $50 \mathrm{~mm}$ wide were used to reinforce the edge or flat surface of test specimens. The experimental sample groups were formed in 34 different ways. Three different holes configurations were prepared. The samples were subjected to the 3 points bend testing in the flatwise and edgewise directions. As a result of tests, bending strength and modulus of elasticity were determined. The data obtained separately in flatwise and edgewise bending tests were subjected to multiple variance analysis. According to experiment results, the lowest values were obtained in the "fabricless" in both tests. The lowest value was obtained as $12.35 \mathrm{~N} \cdot \mathrm{m}^{-2}$ (in PB material) in the group 12, which has samples with the fabric on the edge and 2 holes on the surface in the flatwise test, while the highest value was obtained as $49988 \mathrm{~N} \cdot \mathrm{m}^{-2}$ (in PL material) in the group 19, which has samples with the fabric on the bottom edge and holeless in the edgewise test. According to the materials, the lowest values were as 18.32 N.m-2 in PB material, while the highest values were $49988 \mathrm{~N} \cdot \mathrm{m}^{-2}$ in PL material. It was determined that the BS and MOE values decreased between 0.3 and $49 \%$ in terms of the effect of the hole with fabric on the edge. In the holeless groups, the lowest values $18.32 \mathrm{~N} \cdot \mathrm{m}^{-2}$ in flatwised were obtained in fabricless group in $\mathrm{PB}$, while the highest values $49988 \mathrm{~N} \cdot \mathrm{m}^{-2}$ in edgewised were obtained in the group of fabric on top surface in PL. The results showed that the fabric reinforcement has a positive impact on the strength.
\end{abstract}

KEYWORDS: Wood based panel, bending strength, modulus of elasticity, glass fiber fabric, reinforced. 


\section{INTRODUCTION}

The use of the panel products such as medium-density fiberboard (MDF), particleboard $(\mathrm{PB})$, oriented strandboard (OSB), and plywood (PL) for application areas such as all type furniture or roof and wall sheathing increased in recent years. These panel products need to be drilled several holes during their production. In particular, as Cai and Ross (2010) stated, the bending strength (BS) and modulus of elasticity (MOE) of the panel products are important for the performance characteristics of the panels. As a result, they point out that to understand the effect of holes on strength properties is very important. Eckelman (1975) stated that when constructing furniture frames, it is normally necessary to bore holes through the members to join them together by means of fasteners such as dowels and screws. He specified that these holes must be expected to have a weakening effect upon the members, particularly if they occur at points of high stress. He points out that it is important to take into account any such reductions in strength in the design process to ensure that members are sufficiently designed to withstand the force that would be applied to them in service.

In relation to the $\mathrm{BS}$ and $\mathrm{MOE}$ of wood-based materials, a lot of research has been done to determine the BS and MOE values of the different panels (Hosseinpourpia et al. 2019, Chen et al. 2019, Ghasemi and Moradi 2017, Akgul et al. 2017, Yoshihara 2016, Xu and Que 2016, Chen et al. 2015, Gao et al. 2015, Svoboda et al. 2015, Yildirim et al. 2015, Baidaea et al. 2015, Zhou et al. 2012, Ayrılmış et al. 2010, Bekhta and Marutzky 2007, Alfredsen and Larnoy 2006, and Eckelman 1975). But there is not another information about the effects of the hole on the $\mathrm{BS}$ and MOE of the MDF, PB, OSB, and PL in the literature. Eckelman (1975) developed and presented the expressions which were required to calculate the residual strength of members with holes in them. He carried out static bending tests to determine their BSs on both douglas-fir and $\mathrm{PB}$ beams of rectangular cross section to evaluate the predictive power of the expressions which had been developed. He determined by the test results that observed results dropped nearly $15 \%$ to $20 \%$ below predicted values when holes were drilled near the edge of PB beams tested on edge. In these results obtained, he stated that stress concentrations around the hole in the PB beams could occur. Chen et al. (2019) analyzed the effects of hole sizes on mechanical properties (BS and MOE) of the spruce and Douglas fir samples with and without open-hole. They were prepared four groups (one group without open-hole, and three groups with open-hole which had 13,16 , and $20 \mathrm{~mm}$ diameters). They found that open-hole had significant impact on the bending strength.

A lot of researches have been done to determine the effect of drilled holes on the BS of lumber (Falk et al. 2003), timber (Franke et al. 2015), laminated veneer lumber (LVL) (Ardalany et al. 2013a,b). Falk et al. (2003) concluded that hole location may be as important as hole size. Ardalany et al. (2013a, b) state that the larger holes decreased the capacity of the LVL members by up to $52 \%$. Some researcher was investigated the effect of the laminated timber beams (Hallström 1996) or LVL (Ardalany et al. 2013b) reinforced with glass fiber fabric on the holes. Hallström (1996) stated that when the beams were reinforced, a significant increase of the strength. He indicated that great improvements of strength were obtained with the glass fibers.

In this study, in addition to Eckelman's work, the effect of the hole reinforced with glass fiber fabric (hereinafter referred to as "fabric") on the BS was investigated. The aims of this study were to determine the effect of some factors (material, the hole, the fabric, and the reinforced with the fabric of the negative effect of the hole) on the BS and MOE at the wood based materials (hereinafter referred to as "panels"). 


\section{MATERIALS AND METHODS}

\section{Materials}

In the preparation of the test samples, $18 \mathrm{~mm}$ thick MDF, PB, OSB, and 11-ply PL, were used. The fabrics $19 \mathrm{~mm}$ and $50 \mathrm{~mm}$ wide were used to reinforce the test specimens. These fabrics were fastened with the DTE 1000 epoxy resin and DTS 1105 hardener on the panels. DTE 1000 epoxy resin is a solvent-free epoxy resin. DTS 1105 hardener is a solvent-free epoxy hardener. The epoxy adhesive mixture was prepared by mixing 3 parts of epoxy resin and 1 unit of hardener.

\section{Methods}

Preparation of samples

All panels were cut the $50 \mathrm{~mm} \times 410 \mathrm{~mm}$ using the CNC cutting machine. Pre-tests on MDF were carried out to decide the length $(100,200,300$, and $400 \mathrm{~mm}$ ) of the fabric (wide $50 \mathrm{~mm}$ ) to be glued. The samples were subjected to bending test according to TS EN 310 and ASTM D 1037 standards. According to the test results, it was decided to use the $200 \mathrm{~mm}$ long fabric. Fabrics wide $19 \mathrm{~mm}$ were glued to be $410 \mathrm{~mm}$ long (from one end to the other) on the edge of the samples which having the dimensions of $50 \times 410 \mathrm{~mm}$. The experimental sample groups were formed in 34 different ways. Thus, in total 680 samples were prepared for this study (4 different materials, 34 configurations, 5 repeats).

The samples to be applied to the fabric were treated as follows: $50 \mathrm{~mm}$ wide fabrics were cut $200 \mathrm{~mm}$ long. The mixture of epoxy adhesive was applied on the areas, where the fabric was to be placed, with a brush by a mold. Then, the fabric was placed on these areas and then epoxy adhesive was applied again. Then the nylon bag was laid on. Then the bag was laid on the samples so that the samples would not stick together. After that these specimens were left to dry 2 days. And then, these samples were removed from the molds and they were allowed to dry thoroughly for 2 more days. Then the excess parts overflowing from the edges of the samples were cleaned by cutting with a circular saw machine. The hole locations and dimensions to be opened on the parts is shown in Fig. 1.

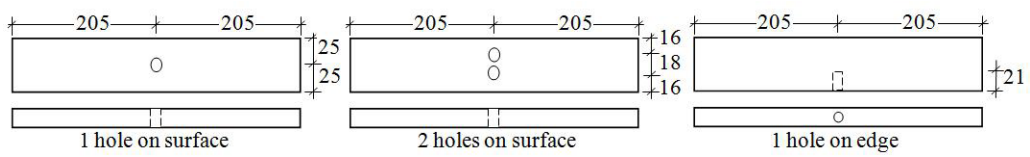

Fig. 1: Hole locations in boards $(18 \times 50 \times 410 \mathrm{~mm})$.

\section{Testing procedures}

The specific gravity (SG), and moisture content (MC), BS, and MOE of the samples were determined according to TS EN 323, TS EN 322, TS EN 310, and ASTM D 1037 standards, respectively. The samples were subjected to the 3 points bend testing in the flatwise and edgewise directions shown in Fig. 2. The samples were placed and were bent in the middle of the length (in the flat and edge position) on the Universal test machine Zwick Roel/Z200 at the Mechanical Laboratory of the Yalova University. 

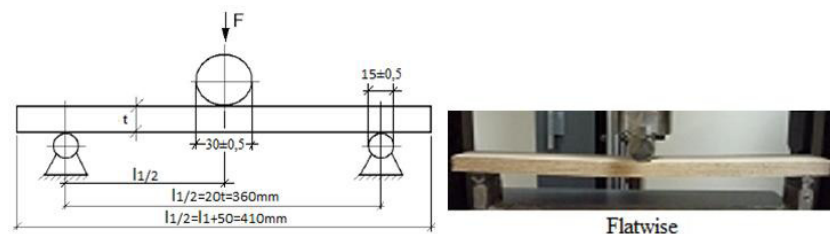

Flatwise

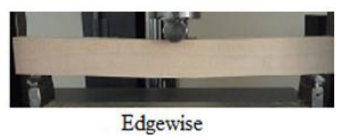

Fig. 2: Bending strength test setup.

The loading speed was adjusted so that failure would occur within an average of $60 \pm 30 \mathrm{sec}$. The $\mathrm{F}_{\max }, \mathrm{BS}$ and $\mathrm{MOE}$ values were calculated automatically by the computerized testing device. The BS was calculated in accordance to Eq.1:

$$
\mathrm{BS}=3 * \mathrm{~F}_{\max }{ }^{*} 1_{1} / 2 * \mathrm{~b}^{*} \mathrm{t} 2 \quad\left(\mathrm{~N} \cdot \mathrm{mm}^{2}\right)
$$

where: BS - bending strength $\left(\mathrm{N} \cdot \mathrm{mm}^{2}\right) ; \mathrm{F}_{\max }$ - the maximum force $(\mathrm{N}) ; \mathrm{l}_{1}$ - the distance between supports $(\mathrm{mm}) ; \mathrm{b}$ - the width of the sample $(\mathrm{mm}) ; \mathrm{t}$ - the height (thickness) of the sample $(\mathrm{mm})$.

The MOE were calculated in accordance with Eq. 2:

$$
\mathrm{MOE}=1_{1}{ }^{3}\left(\mathrm{~F}_{2}-\mathrm{F}_{1}\right) / 4^{*} \mathrm{~b}^{*} \mathrm{t}^{3}\left(\mathrm{a}_{2}-\mathrm{a}_{1}\right) \quad\left(\mathrm{N} \cdot \mathrm{mm}^{2}\right)
$$

where: MOE - modulus of elasticity $\left(\mathrm{N} \cdot \mathrm{mm}^{-2}\right) ; \mathrm{F}_{2}-\mathrm{F}_{1}$ - the load increase in the proportional section of the load-deflection diagram $(\mathrm{N}) ; \mathrm{F}_{1}=$ approx. $10 \%$ of the largest force $(\mathrm{N}) ; \mathrm{F}_{2}=$ approx. $40 \%$ of the largest force $(\mathrm{N}) ; \mathrm{a}_{2}-\mathrm{a}_{1}-$ the deflection increase in the half of the sample length corresponding to the load increase $(\mathrm{mm})$.

In determination of the MOE in bending, the 1/3 amount of the greatest force obtained in the BS test was chosen as the elastic region. Load-deflection graphs measured with \pm 0.01 (unit) sensitivity corresponding to each $50 \mathrm{~N}$ force applied were plotted. And the $10 \%$ and $40 \%$ values of the failure load were recorded. And the $10 \%$ and $40 \%$ values of the failure load were recorded. The MOE was calculated by using the recorded these values in the elastic deformation zone of the drawn curve.

\section{Analyses of the data}

The data obtained separately in flatwise and edgewise bending tests were subjected to multiple variance analysis in SPSS program. And 16 (in flatwise) or 18 (in edgewise) experimental groups, 4 material types, 4 hole groups, 3 (in flatwise) or 4 (in flatwise) hole location groups, 3 fabric groups and 4 fabric location groups on BS and MOE effects were determined. The relationship between these main factors was determined at $\mathrm{p}<0.001$ significance level. When these main factors or their interactions with each other were found to be statistically significant, Duncan test was applied to determine the differences between the groups and to establish homogeneous groups.

\section{RESULTS AND DISCUSSION}

Some physical and mechanical properties of the panels used in the experiments were given in Tab. 1. The BS and MOE values of the raw materials (control samples) were in parallel with the values given in chapter 12 of the wood handbook written by Cai and Ross (2010). 
Tab. 1: Density and moisture content of wood-based panels.

\begin{tabular}{|c|c|c|c|c|}
\hline & MDF & PB & OSB & PL \\
\hline Moisture content (\%) & 6.9 & 8.1 & 8.6 & 10.9 \\
\hline Density $\left({\left.\mathrm{g} \cdot \mathrm{cm}^{-3}\right)}\right.$ & 0.759 & 0.642 & 0.564 & 0.62 \\
\hline $\mathrm{BS}\left(\mathrm{N} \cdot \mathrm{mm}^{-2}\right)$ & 35.99 & 18,29 & 22,73 & 63.9 \\
\hline $\operatorname{MOE}\left(\mathrm{N} \cdot \mathrm{mm}^{-2}\right)$ & 3410 & 3241 & 4848 & 8894 \\
\hline
\end{tabular}

The results obtained from the pre-tests were given in Tab. 2. As shown in the table, it was determined that the results of the samples of 20,30 , and $41 \mathrm{~cm}$ long glued fabric were almost the same. Therefore, the length of the fabric to be glued to the surfaces of the test samples was determined to be $20 \mathrm{~cm}$.

Tab. 2: Pre-test bending test results (MDF).

\begin{tabular}{|c|c|c|c|c|c|c|c|c|c|c|c|c|}
\hline Fabric & \multicolumn{5}{|c|}{ Flatwised } & \multicolumn{5}{c|}{ Edgewised } \\
\cline { 2 - 13 } length & Control & $5 \mathrm{~cm}$ & $10 \mathrm{~cm}$ & $20 \mathrm{~cm}$ & $30 \mathrm{~cm}$ & $41 \mathrm{~cm}$ & Control & $5 \mathrm{~cm}$ & $10 \mathrm{~cm}$ & $20 \mathrm{~cm}$ & $30 \mathrm{~cm}$ & $41 \mathrm{~cm}$ \\
\hline $\begin{array}{c}\text { F } \mathbf{m a x} \\
(\mathbf{N})\end{array}$ & 1030 & 1050 & 1330 & 1650 & 1440 & 1530 & 2600 & 2570 & 2630 & 2780 & 2960 & 3100 \\
\hline $\begin{array}{c}\text { MOE } \\
\left(\mathbf{N} \cdot \mathbf{m m}^{-2}\right)\end{array}$ & 3350 & 3480 & 3380 & 3910 & 3890 & 3890 & 20300 & 21600 & 22700 & 21300 & 21300 & 22900 \\
\hline
\end{tabular}

The BS and MOE results obtained in experiments were given in Tab. 3. The results show that, in the flatwise test, the lowest value as $12.35 \mathrm{~N} \cdot \mathrm{m}^{-2}$ (in PB material) was obtained in the group 12, which has samples with the fabric on the edge and 2 holes on the surface, while the highest value as $12912 \mathrm{~N} \cdot \mathrm{m}^{-2}$ (in PL material) was obtained in the group 2, which has samples with the fabric on the bottom surface and holeless. On the other hand, in the edge test, the lowest value was obtained as $30.27 \mathrm{~N} \cdot \mathrm{m}^{-2}$ (in PB material) in the group 29, which has samples fabricless and 1 hole on the bottom edge, while the highest value was obtained as $49988 \mathrm{~N} \cdot \mathrm{m}^{-2}$ (in PB material) in the group 19, which has samples with the fabric on the bottom edge and holeless.

In the flatwise tests, according to the tests groups, the highest BS and MOE values were obtained in the "holeless-fabric on bottom surface" group (group no 2) for MDF, PB, and PL materials, and in the "holeless-fabric on top surface" group (group no 3) for OSB material. Additionally, the lowest $\mathrm{BS}$ values for $\mathrm{MDF}$ and $\mathrm{PB}$ materials and the lowest $\mathrm{MOE}$ values for $\mathrm{PB}$ material were obtained in the "2 holes on surface-fabric on edge" group (group no 12), while other lowest values were obtained in the " 2 holes on surface-fabricless" group (group no 9).

On the other hand, in the edgewise tests, the highest BS values for MDF and PB materials were obtained in the " 1 hole on surface-fabric on bottom edge" group (group no 23), while other highest values were obtained in the "holeless-fabric on bottom edge" group (group no 19). Additionally, the lowest BS values were obtained; in the "1 hole-fabric on bottom edge" group (group no 33) for PL material, and in the "1 hole on bottom edge-fabricless" group (group no 29) for other material, while the lowest MOE values were determined in the " 1 hole on top edgefabric on surface" group (group no 32) for MDF material, in the "1 hole on surface-fabricless" group (group no 21) for PB material, in the "2 holes-fabric on surface" group (group no 26) in OSB material, and in the " 1 hole on top edge-fabricless" group (group no 30 ) for PL material. 
Tab. 3: Test results $\left(N \cdot m^{-2}\right)$.

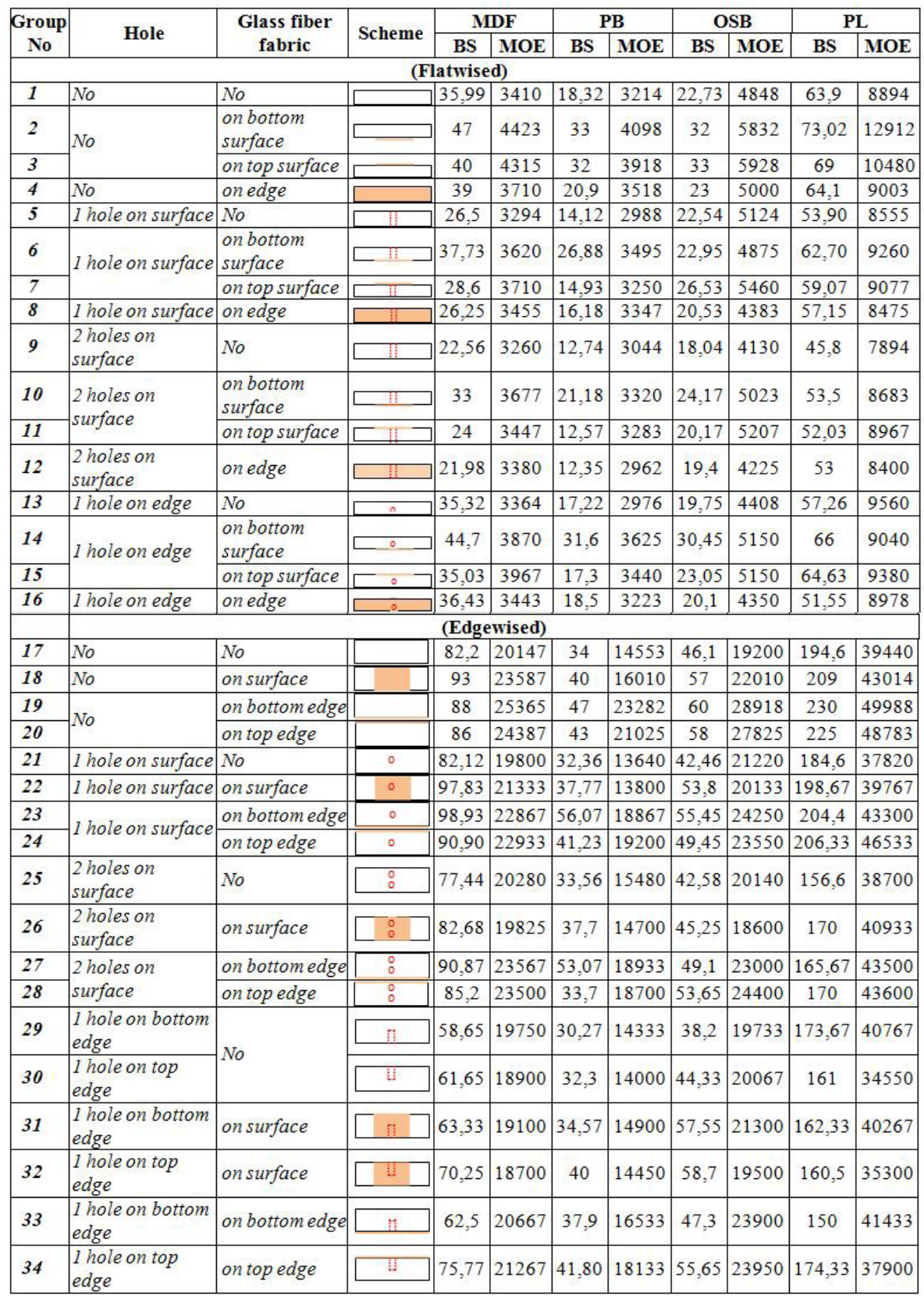

In Tab. 3, according to the flatwise tests, the presence of 2 holes on the surface of the sample caused much more strength decrease. On the other hand, according to the edgewise tests, the 
Vol. 65 (3): 2020

presence of 1 hole on the edge of the sample caused much more strength decrease than others.

When the test results were evaluated in terms of materials, in both flatwise and edgewise tests, the BS and MOE values were the lowest in PB, the highest in the PL. The reason why these values are high or low can be explained as the BS and MOE values of the material itself are higher or lower than others. According to the results of variance analysis, it was determined that 4 different homogeneous groups were formed (Tab. 4).

Tab. 4: Homogenous groups $(H G)$ according to the materials $\left(N \cdot m^{-2}\right)$.

\begin{tabular}{|c|c|c|c|c|c|c|c|c|}
\hline \multirow{2}{*}{ Materials } & \multicolumn{4}{|c|}{ Flatwised } & \multicolumn{4}{|c|}{ Edgewised } \\
\cline { 2 - 9 } & BS & HG & MOE & HG & BS & HG & MOE & HG \\
\hline MDF & 33.38 & B & 3647 & C & 80.41 & B & 21443 & C \\
\hline PB & 19.99 & D & 3356 & D & 39.24 & D & 16697 & D \\
\hline OSB & 23.65 & C & 4943 & B & 50.81 & C & 22317 & B \\
\hline PL & 59.16 & A & 9222 & A & 183.15 & A & 41422 & A \\
\hline
\end{tabular}

The test results of the "fabricless" groups (group 1, 5, 9, and 13 in flatwise tests and group $17,21,25,29$, and 30 in edgewise tests) were evaluated to determine the effect of the hole. As a result, BS values were found generally that in the flatwise tests, the "holeless" groups was high and the " 2 holes on surface" groups was low, whereas, in the edgewise tests, the "holeless" groups was high and the " 1 hole on edge" groups was low. The MOE values were determined generally; the "holeless" was high in both tests; the " 2 holes on surface" in flatwise tests, and also " 1 hole on edge" in edgewise tests were low. According to these results, it was clear that the existence of a hole on the material and the increase in the number of such holes reduces the strength. The reason for this decrease can be explained as the reduction of the cross-section area of the material to react to the applied load. In parallel with the results obtained in the studies of Eckelman (1975), Falk et al. (2003), and Chen et al. (2019), the hole was determined to reduce strength. The effect of the hole was evaluated statistically and their homogeneous groups in Tab. 5 were obtained according to variance analysis. 4 homogeneous groups were obtained for BS in PB and $\mathrm{MDF}$ and for MOE in MDF and PL in the flatwise tests and for BS in MDF and for MOE in $\mathrm{PB}$ in the edgewise tests. 3 homogeneous groups were observed in others.

Tab. 5: Homogenous groups (HG) according to the hole.

\begin{tabular}{|c|c|c|c|c|c|c|c|c|c|c|c|c|c|c|c|c|}
\hline \multirow{3}{*}{ Groups } & \multicolumn{8}{|c|}{ Flatwised } & \multicolumn{8}{|c|}{ Edgewised } \\
\hline & \multicolumn{2}{|c|}{ MDF } & \multicolumn{2}{|c|}{ PB } & \multicolumn{2}{|c|}{ OSB } & \multicolumn{2}{|c|}{ PL } & \multicolumn{2}{|c|}{ MDF } & \multicolumn{2}{|c|}{ PB } & \multicolumn{2}{|c|}{ OSB } & \multicolumn{2}{|c|}{ PL } \\
\hline & BS & HG & BS & HG & BS & HG & BS & HG & BS & HG & BS & HG & BS & HG & BS & HG \\
\hline 1 & 41 & $\mathrm{~A}$ & 26 & $\mathrm{~A}$ & 28 & $\mathrm{~A}$ & 68 & $\mathrm{~A}$ & 87 & $\mathrm{~B}$ & 41 & $\mathrm{~A}, \mathrm{~B}$ & 55 & A & 215 & A \\
\hline 2 & 30 & $\mathrm{C}$ & 18 & $\mathrm{C}$ & 23 & B & 58 & $\mathrm{~B}$ & 93 & A & 42 & $\mathrm{~A}$ & 50 & $\mathrm{~B}$ & 199 & B \\
\hline 3 & 25 & $\mathrm{D}$ & 15 & $\mathrm{D}$ & 21 & $\mathrm{C}$ & 51 & $\mathrm{C}$ & 84 & $\mathrm{C}$ & 40 & $\mathrm{~B}$ & 48 & $\mathrm{C}$ & 166 & C \\
\hline 4 & 38 & $\mathrm{~B}$ & 21 & $\mathrm{~B}$ & 23 & $\mathrm{~B}$ & 60 & $\mathrm{~B}$ & 65 & $\mathrm{D}$ & 36 & $\mathrm{C}$ & 50 & $\mathrm{~B}$ & 164 & $\mathrm{C}$ \\
\hline & MOE & HG & MOE & HG & MOE & HG & MOE & HG & MOE & HG & MOE & HG & MOE & HG & MOE & $\mathrm{HG}$ \\
\hline 1 & 3965 & $\mathrm{~A}$ & 3687 & $\mathrm{~A}$ & \begin{tabular}{|l|}
5402 \\
\end{tabular} & $\mathrm{~A}$ & 10322 & $\mathrm{~A}$ & 23371 & A & 18718 & $\mathrm{~A}$ & 24488 & $\mathrm{~A}$ & 45306 & $\mathrm{~A}$ \\
\hline 2 & 3520 & $\mathrm{C}$ & 3270 & $\mathrm{~B}$ & \begin{tabular}{|l|}
4961 \\
\end{tabular} & $\mathrm{~B}$ & 8842 & $\mathrm{C}$ & 21733 & $\mathrm{~B}$ & 16377 & $\mathrm{C}$ & 22288 & $\mathrm{~B}$ & 41855 & $\mathrm{~B}$ \\
\hline 3 & 3441 & $\mathrm{D}$ & 3153 & $\mathrm{C}$ & 4646 & $\mathrm{C}$ & 8486 & $\mathrm{D}$ & 21793 & $\mathrm{~B}$ & 16953 & B & 21535 & $\mathrm{C}$ & 41683 & $\mathrm{~B}$ \\
\hline 4 & 3661 & B & 3316 & B & 4764 & $B, C$ & 9239 & B & 19731 & $\mathrm{C}$ & 15392 & $\mathrm{D}$ & 21408 & $\mathrm{C}$ & 38370 & $\mathrm{C}$ \\
\hline
\end{tabular}

Groups: $1=$ holeless, $2=1$ hole on surface, $3=2$ holes on surface, $4=1$ hole on edge.

When the results were analyzed statistically according to the hole location, homogeneous groups were obtained as seen in Tab. 6 . 
Tab. 6: Homogenous groups (HG) according to the hole location.

\begin{tabular}{|c|c|c|c|c|c|c|c|c|c|c|c|c|c|c|c|c|}
\hline \multicolumn{17}{|c|}{ Flatwised } \\
\hline \multirow{2}{*}{ Groups } & \multicolumn{2}{|c|}{ MDF } & \multicolumn{2}{|c|}{ PB } & \multicolumn{2}{|c|}{ OSB } & \multicolumn{2}{|c|}{ PL } & \multicolumn{2}{|c|}{ MDF } & \multicolumn{2}{|c|}{ PB } & \multicolumn{2}{|c|}{ OSB } & \multicolumn{2}{|c|}{ PL } \\
\hline & BS & $\mathrm{HG}$ & $\mathrm{BS}$ & $\mathrm{HG}$ & $\mathrm{BS}$ & $\mathrm{HG}$ & BS & $\mathrm{HG}$ & MOE & $\mathrm{HG}$ & MOE & HG & MOE & $\mathrm{HG}$ & MOE & $\mathrm{HG}$ \\
\hline 1 (holeless) & 41 & $\mathrm{~A}$ & 26 & $\mathrm{~A}$ & 28 & $\mathrm{~A}$ & 68 & $\mathrm{~A}$ & \begin{tabular}{|l|}
3965 \\
\end{tabular} & $\mathrm{~A}$ & \begin{tabular}{|l|}
3687 \\
\end{tabular} & $\mathrm{~A}$ & 5402 & $\mathrm{~A}$ & 10322 & $\mathrm{~A}$ \\
\hline $\begin{array}{c}2 \text { (on } \\
\text { surface) }\end{array}$ & 28 & $\mathrm{C}$ & 17 & $\mathrm{C}$ & 22 & B & 55 & $\mathrm{C}$ & 3480 & $\mathrm{C}$ & 3211 & $\mathrm{C}$ & 4803 & B & 8664 & $\mathrm{C}$ \\
\hline 3 (on edge) & 38 & $\mathrm{~B}$ & 21 & $\mathrm{~B}$ & 23 & $\mathrm{~B}$ & 60 & $\mathrm{~B}$ & 3661 & $\mathrm{~B}$ & 3316 & $\mathrm{~B}$ & 4764 & $\mathrm{~B}$ & 9239 & $\mathrm{~B}$ \\
\hline \multicolumn{17}{|c|}{ Edgewised } \\
\hline \multirow{2}{*}{ Groups } & \multicolumn{2}{|c|}{ MDF } & \multicolumn{2}{|c|}{ PB } & \multicolumn{2}{|c|}{ OSB } & \multicolumn{2}{|c|}{ PL } & \multicolumn{2}{|c|}{ MDF } & \multicolumn{2}{|c|}{ PB } & \multicolumn{2}{|c|}{ OSB } & \multicolumn{2}{|c|}{ PL } \\
\hline & BS & $\mathrm{HG}$ & $\mathrm{BS}$ & $\mathrm{HG}$ & $\mathrm{BS}$ & $\mathrm{HG}$ & BS & $\mathrm{HG}$ & MOE & HG & MOE & HG & MOE & HG & MOE & $\mathrm{HG}$ \\
\hline 1 (holeless) & 87 & $\mathrm{~A}$ & 41 & $\mathrm{~A}$ & 56 & $\mathrm{~A}$ & 215 & $\mathrm{~A}$ & \begin{tabular}{|l|}
23371 \\
\end{tabular} & $\mathrm{~A}$ & 18718 & $\mathrm{~A}$ & 24488 & $\mathrm{~A}$ & 45306 & $\mathrm{~A}$ \\
\hline $\begin{array}{c}2 \text { (on } \\
\text { surface) }\end{array}$ & 88 & A & 41 & A & 49 & $\mathrm{C}$ & 182 & B & 21763 & B & 16665 & B & 21912 & B & 41769 & B \\
\hline $\begin{array}{c}3 \text { (on } \\
\text { bottom } \\
\text { edge) }\end{array}$ & 62 & C & 34 & $\mathrm{C}$ & 48 & $\mathrm{C}$ & 162 & $\mathrm{C}$ & 19839 & $\mathrm{C}$ & 15256 & $\mathrm{C}$ & 21644 & B, C & 40822 & $\mathrm{C}$ \\
\hline $\begin{array}{c}4 \text { (on top } \\
\text { edge) }\end{array}$ & 69 & B & 38 & B & 53 & B & 165 & $\mathrm{C}$ & 19622 & $\mathrm{C}$ & 15528 & $\mathrm{C}$ & 21172 & $\mathrm{C}$ & 35917 & D \\
\hline
\end{tabular}

In the flatwise tests, 2 different homogeneous groups were formed in both BS and MOE values of OSB. In edgewise tests, 4 different homogeneous groups were obtained for the MOE values of PL. In the others, 3 different homogeneous groups were formed. The highest values were obtained mostly in the "holeless" groups both tests. The lowest BS and MOE were obtained in the "on surface" groups in the flatwise tests. the lowest BS were determined mostly the "bottom edge" groups and the lowest $\mathrm{MOE}$ were determined generally in the "top edge" group in the edgewise tests. As a result, Falk et al. (2003) stated that the hole location affects the bending strength.

The groups without holes (in groups 1-4, 17-20) were evaluated to determine the effect of the fabric (Tab. 3). The lowest values were obtained as $18.32 \mathrm{~N} \cdot \mathrm{m}^{-2}$ (in flatwised) and as $34 \mathrm{~N} \cdot \mathrm{m}^{-2}$ (in edgewised) in fabricless groups in PB, while the highest values were obtained as $10480 \mathrm{~N} \cdot \mathrm{m}^{-2}$ (in groups of fabric on top surface in flatwised) and $49988 \mathrm{~N} \cdot \mathrm{m}^{-2}$ (in groups of fabric on bottom edge in edgewised) in PL. The highest BS and MOE were obtained; in the "on top surface" group for OSB and PL and in the "on bottom surface" group for MDF and PB in the flatwise tests (in groups 1-4); in the "on bottom edge" group in all materials except for the BS value (was obtained in the "on surface" group) of the OSB in edgewise tests. In flatwise tests, as can be seen, in all materials, the sample group which was "fabric on surface" was seen to cause higher strength. However, in OSB, it was determined that the fabric on the bottom surface of the sample was more effective than the fabric on the top surface. The reason for this is due to the structural features of the OSB as seen in the failure shapes. It can be confirmed as the top surface of the material was swelled and deformed by the fabric on the bottom surface.

When the test results were analyzed statistically in terms of the effect of fabric, homogeneity groups that obtained according to variance analysis results were obtained as shown in Tab. 7. In all materials, the highest values were obtained; in the "fabric on surface" in the flatwise tests; in the "fabric on edge" in the edgewise tests. The lowest values were obtained in the "fabricless" in both tests. It was determined that the fabric on surface provided compared to the fabricless samples an increase of; between 12 and $52 \%$ in the flatwise tests; between 1 and $28 \%$ in the edgewise tests. Statistically, it was seen that the "fabric on surface" was in the highest. It was also clearly seen that the effect of the fabric on surface was higher than the effect of the fabric on edge. Similar to 
Vol. 65 (3): 2020

these results, Hallström (1996) stated that when the beams were reinforced, a significant increase of the strength.

Tab. 7: Homogenous groups $(H G)$ according to the fabric.

\begin{tabular}{|c|c|c|c|c|c|c|c|c|c|c|c|c|c|c|c|c|}
\hline \multirow{3}{*}{ Groups } & \multicolumn{8}{|c|}{ Flatwised } & \multicolumn{8}{|c|}{ Edgewised } \\
\hline & \multicolumn{2}{|c|}{ MDF } & \multicolumn{2}{|c|}{ PB } & \multicolumn{2}{|c|}{ OSB } & \multicolumn{2}{|c|}{ PL } & \multicolumn{2}{|c|}{ MDF } & \multicolumn{2}{|c|}{ PB } & \multicolumn{2}{|c|}{ OSB } & \multicolumn{2}{|c|}{ PL } \\
\hline & BS & HG & BS & HG & BS & HG & BS & HG & BS & HG & BS & HG & BS & HG & BS & HG \\
\hline 1 & 30 & $\mathrm{C}$ & 16 & $\mathrm{C}$ & 21 & B & 55 & B & 72 & $\mathrm{C}$ & 33 & $\mathrm{C}$ & 43 & B & 174 & $\mathrm{C}$ \\
\hline 2 & 36 & A & 24 & A & 27 & A & 63 & A & 81 & B & 38 & B & 55 & A & 180 & B \\
\hline 3 & 31 & B & 17 & B & 21 & $B$ & 57 & $B$ & 85 & A & 44 & $\mathrm{~A}$ & 54 & A & 191 & $\mathrm{~A}$ \\
\hline & MOE & HG & MOE & HG & MOE & HG & MOE & HG & MOE & HG & MOE & HG & MOE & HG & MOE & HG \\
\hline 1 & 3332 & $\mathrm{C}$ & 3056 & $\mathrm{C}$ & 4628 & B & 8726 & $\mathrm{~B}$ & 19775 & $\mathrm{C}$ & 14401 & B & 20072 & $\mathrm{~B}$ & 38255 & $\mathrm{C}$ \\
\hline 2 & 3879 & A & 3554 & $\mathrm{~A}$ & 5328 & A & 9725 & $\mathrm{~A}$ & 20509 & B & 14772 & B & 20309 & B & 39856 & $\mathrm{~B}$ \\
\hline 3 & 3497 & B & 3263 & $\mathrm{~B}$ & 4490 & $B$ & 8714 & $\mathrm{~B}$ & 23069 & A & 19334 & $\mathrm{~A}$ & 24974 & $\mathrm{~A}$ & 44380 & $\mathrm{~A}$ \\
\hline
\end{tabular}

Groups: $1=$ fabricless, 2 = fabric on surface, $3=$ fabric on edge.

The tests results were evaluated statistically in terms of the fabric location. And the obtained homogeneous groups were given in Tab. 8.

Tab. 8: Homogenous groups $(H G)$ according to the fabric location.

\begin{tabular}{|c|c|c|c|c|c|c|c|c|c|c|c|c|c|c|c|c|}
\hline \multirow{3}{*}{ Groups } & \multicolumn{8}{|c|}{ Flatwised } & \multicolumn{8}{|c|}{ Edgewised } \\
\hline & \multicolumn{2}{|c|}{ MDF } & \multicolumn{2}{|c|}{ PB } & \multicolumn{2}{|c|}{ OSB } & \multicolumn{2}{|c|}{ PL } & \multicolumn{2}{|c|}{ MDF } & \multicolumn{2}{|c|}{ PB } & \multicolumn{2}{|c|}{ OSB } & \multicolumn{2}{|c|}{ PL } \\
\hline & BS & HG & BS & HG & BS & HG & BS & HG & BS & HG & BS & HG & BS & HG & BS & HG \\
\hline 1 & 30.09 & $\mathrm{D}$ & 15.6 & $\mathrm{D}$ & 20.77 & B & 55.22 & B & 72.41 & $\mathrm{C}$ & 32.5 & $\mathrm{D}$ & 42.73 & B & 174.09 & $\mathrm{D}$ \\
\hline 2 & 40.61 & $\mathrm{~A}$ & 28.16 & $\mathrm{~A}$ & 27.39 & $\mathrm{~A}$ & 63.81 & $\mathrm{~A}$ & 81.42 & B & 38.01 & $\mathrm{C}$ & 54.46 & $\mathrm{~A}$ & 180.1 & $\mathrm{C}$ \\
\hline 3 & 31.91 & B & 19.2 & $\mathrm{~B}$ & \begin{tabular}{|l|}
25.69 \\
\end{tabular} & $\mathrm{~A}$ & 61.18 & $\mathrm{~A}$ & 85.08 & $\mathrm{~A}$ & 48.51 & $\mathrm{~A}$ & \begin{tabular}{|l|}
52.96 \\
\end{tabular} & $\mathrm{~A}$ & 187.52 & $\mathrm{~B}$ \\
\hline 4 & 30.91 & $\mathrm{C}$ & \begin{tabular}{|l|}
16.98 \\
\end{tabular} & $\mathrm{C}$ & 20.76 & B & \begin{tabular}{|l|}
56.45 \\
\end{tabular} & $\mathrm{~B}$ & 84.47 & $\mathrm{~A}$ & 39.93 & B & \begin{tabular}{|l|}
54.19 \\
\end{tabular} & $\mathrm{~A}$ & \begin{tabular}{|l|}
193.92 \\
\end{tabular} & $\mathrm{~A}$ \\
\hline & MOE & HG & MOE & HG & MOE & HG & MOE & HG & MOE & HG & MOE & HG & MOE & HG & MOE & HG \\
\hline 1 & 3332 & $\mathrm{D}$ & 3056 & $\mathrm{D}$ & 4628 & B & 8726 & $\mathrm{C}$ & 19775 & $\mathrm{C}$ & 14401 & $\mathrm{~B}$ & 20072 & B & 38255 & $\mathrm{C}$ \\
\hline 2 & 3897 & $\mathrm{~A}$ & 3635 & $\mathrm{~A}$ & 5220 & $\mathrm{~A}$ & 9974 & $\mathrm{~A}$ & 20509 & B & 14772 & B & 20309 & B & 39856 & $\mathrm{~B}$ \\
\hline 3 & 3860 & B & 3473 & B & 5436 & A & 9476 & B & 23116 & $\bar{A}$ & 19404 & A & 25017 & $\mathrm{~A}$ & 44555 & $\mathrm{~A}$ \\
\hline 4 & 3497 & $\mathrm{C}$ & 3263 & C & 4490 & B & 8714 & C & 23022 & A & 19265 & A & 24931 & A & 44204 & A \\
\hline
\end{tabular}

Groups: $1=$ fabricless, $2=$ on bottom surface, $3=$ on top surface, $4=$ on edge.

Furthermore, the results were examined in terms of the effect of the hole with fabric on the edge (groups 4, 8, 12, and 16) in the flatwise tests. And, the BS and MOE values were as follows respectively it was found. It decreased in the " 1 hole on edge" group, $7 \%$ and $7 \%$ for MDF, $12 \%$ and $8 \%$ for $\mathrm{PB}, 13 \%$ and $13 \%$ for OSB, and $20 \%$ and $0.3 \%$ for PL. It decreased in the " 1 hole on surface" group, $49 \%$ and $7 \%$ for MDF, $23 \%$ and $5 \%$ for $\mathrm{PB}, 11 \%$ and $12 \%$ for OSB, and $11 \%$ and $6 \%$ for PL. It decreased in the " 2 holes on surface" group, $44 \%$ and $9 \%$ for MDF, $41 \%$ and $16 \%$ for $\mathrm{PB}, 16 \%$ and $19 \%$ for OSB, and $17 \%$ and $7 \%$ for PL. According to these ratios, the presence of 2 holes on the surface was seen to cause the most decrease in strength.

\section{Failure mode}

In the "fabricless" groups, all samples except MDF and OSB samples in edgewise were cracked. MDF samples in edgewise were broken. Any deformation was seen in OSB samples. However, a cracking sound was heard during the experiment. Possibly separations in the inner layers of the OSB have occurred.

Only MDF samples in groups 17, 21, 23, 24, 25, 27-30, 33, and 34 were broken. On the other hand, in the groups 6, 14, and 23 in OSB was surged by squeeze from the side of the load 
line applied to the top surface. In PL, in groups 1, 5, 6-11, 14-16, 22, and 32, the layers of the PL were separated from each other. Besides, the almost other samples were cracked.

The failure shapes of the "fabric on edge" samples (in groups 4, 8, 12, and 16) in flatwise tests similar. The fabric was separated from the edge and the material was cracked. On the other hand, it was found that the reduction ratio in strength for the samples with hole on the edge was less than the others (Tab. 3). As it was understood from the shape of deformation, the fabric on the edge carried more load than the others and as a result, the fabric was opened by wriggle from below to the hole. It also appears that the samples were broken up to the hole and cracked upwards through the hole. On the other hand, in other materials, the fabric was slightly opened and the material was cracked on the bottom surface. In addition, it was seen that the PL samples were separated from its layers.

The "hole on edge" group had been determined to have higher strength than the "1 hole on surface" group and " 2 holes on surface" group. In addition, in the " 1 hole on edge" group, the material was cracked by being squeezed from the hole to both upwards and towards the side of the load line applied on the top surface. This was shown that the fabric was higher than the strength of the material. In the "fabric on bottom surface" and " 1 hole on edge" groups, in the MDF, OSB, and PL, the fabric was not deformed, and the material was not also cracking. In PL, the material was separated from the layer at the level of the hole. The fabric in PB was opened and torn and the material was cracked.

\section{CONCLUSIONS}

According to the results, in the flatwise test, the lowest value was obtained as $12.35 \mathrm{~N} \cdot \mathrm{m}^{-2}$ in the samples with the fabric on the edge and 2 holes on the surface for PB material, while the highest value was obtained as $12912 \mathrm{~N} \cdot \mathrm{m}^{-2}$ in the samples with the fabric on the bottom surface and holeless for PL material. On the other hand, in the edge test, the lowest value was obtained as $30.27 \mathrm{~N} \cdot \mathrm{m}^{-2}$ in the samples fabricless and 1 hole on the bottom edge for PB material, while the highest value was obtained as $49988 \mathrm{~N} \cdot \mathrm{m}^{-2}$ in the samples with the fabric on the bottom edge and holeless for PB material.

According to the materials, for the BS and MOE values in both tests, the lowest values were as $18.32 \mathrm{~N} \cdot \mathrm{m}^{-2}$ for $\mathrm{BS}$ and as $2962 \mathrm{~N} \cdot \mathrm{m}^{-2}$ for MOE in $\mathrm{PB}$, while the highest values were as $230 \mathrm{~N} \cdot \mathrm{m}^{-2}$ for BS and as $49988 \mathrm{~N} \cdot \mathrm{m}^{-2}$ for MOE in the PL.

In the holeless groups, the lowest values were obtained as $18.32 \mathrm{~N} \cdot \mathrm{m}^{-2}$ (in flatwised) and as $34 \mathrm{~N} \cdot \mathrm{m}^{-2}$ (in edgewised) in fabricless groups in PB, while the highest values were obtained as $10480 \mathrm{~N} \cdot \mathrm{m}^{-2}$ (in groups of fabric on top surface in flatwised) and $49988 \mathrm{~N} \cdot \mathrm{m}^{-2}$ (in groups of fabric on bottom edge in edgewised) in PL.

It was determined that the BS and MOE values of the samples with hole in terms of the effect of the hole with fabric on the edge decreased between 0.3 and $49 \%$. The existence of a hole on the material and the increase in the number of such holes reduces the strength. The presence of hole on the sample caused much more strength decrease.

The lowest values were obtained in the "fabricless" in both tests. It has been determined that the fabric on the surface increases resistance up to $52 \%$ compared to fabricless samples. The fabric on the bottom surface of the sample was more effective than the fabric on the top surface. The effect of the fabric on the surface of the sample was higher than the effect of the fabric on the edge of the sample. The effect of the fabric on the edge of the sample was cause for increase compare to the samples the fabricless. If the sample has any holes, it may be advisable to reinforce, for example, with a fabric. 


\section{ACKNOWLEDGEMENTS}

This study was supported by the Research Fund of Yalova University. Project Number: 2014/ BAP/090.

\section{REFERENCES}

1. Alfredsen, G., Larnoy, E., 2006: Dynamic MOE testing of wood: the influence of wood protecting agents and moisture content on ultrasonic pulse and resonant vibration. Wood Research 51(1): 11-20.

2. Ardalany, M., Fragiacomo, M., Carradine, D., Moss, P., 2013a: Experimental behavior of laminated veneer lumber (LVL) joists with holes and different methods of reinforcement. Engineering Structures 56: 2154-2164.

3. Ardalany, M., Fragiacomo, M., Moss, P., Deam, B., 2013b: An analytical model for design of reinforcement around holes in laminated veneer lumber (LVL) beams. Materials and Structures 46: 1811-1831.

4. Akgul, M., Uner, B., Camllibel, O., Ayata, Umit., 2017: Manufacture of medium density fiberboard (MDF) panel from agribased lignocellulosic biomass. Wood Research 62(4): 615-624.

5. ASTM D 1037, 1973: Evaluating the properties of wood-base fiber and particle panel materials.

6. Ayrılmıs, N., Buyuksarı, U., As, N., 2010: Bending strength and modulus of elasticity of wood-based panels at cold and moderate temperatures. Cold Regions Science and Technology 63: 40-43.

7. Bekhta, P., Marutzky, R., 2007: Bending strength and modulus of elasticity of particleboards at various temperatures. Holz als Roh-und Werkstoff 65: 163-165.

8. Biadaea, T., Czarnecki, R., Dukarska, D., 2015: Attempt to produce flexible plywood with use of Europe wood species. Wood Research 60(2): 317-328.

9. Cai, Z., Ross, R.J., 2010: Wood handbook. Chapter 12: Mechanical properties of woodbased composite materials, 12 p. Report GTR-190. Forest Products Laboratory. Madison. WI, U.S.

10. Chen, D., Zhang, W., Shen, W., Jin, Z., Zhang, Q. 2019: Investigation on the mechanical properties of open-hole spruce and Douglas fir. Wood Research 64(1): 155-164.

11. Chen, H.T., Li, T., Zhou, C.L., Li, Y.Q. Song, R.X., 2015: Experimental evaluation on mechanical performance of OSB webbed parallel strand bamboo I-joist with holes in the web. Construction \& Building Materials 101: 91-98.

12. Eckelman, C.A., 1975: Effects of holes on the bending strength of wood and particleboard parts. Wood Research Laboratory. Research Bulletin No. 922, 8 pp.

13. Falk, R.H., DeVisser, D., Plume, G.R., Fridley, K.J., 2003: Effect of drilled holes on the bending strength of large dimension Douglas-fir lumber. Forest Products Journal 53(5): 55-60.

14. Franke, F., Franke, B., Harte, A.M., 2015: Failure modes and reinforcement techniques for timber beams-state of the art. Construction and Building Materials 97: 2-13.

15. Gao, H., Yang, X.C., Zhang, C., 2015: Experimental and numerical analysis of three-point bending fracture of pre-notched asphalt mixture beam. Construction \& Building Materials 90: 1-10. 
16. Ghasemi, A.R., Moradi, M., 2017: Effect of thermal cycling and open-hole size on mechanical properties of polymer matrix composites. Polymer Testing 59: 20-28.

17. Hallström, H., 1996: Glass fibre reinforced holes in laminated timber beams. Wood Science and Technology 30: 323-337.

18. Hosseinpourpia, R., Mai, C., Taghiyari, H.R., 2019: Properties of medium-density fibreboards bonded with dextrin-based wood adhesive. Wood Research 64(2): 185-194.

19. Svoboda, T., Ruman, D., Gaff, M., Gasparik, M., Miftieva, E., Dundek, L., 2015: Bending characteristics of multilayered soft and hardwood materials. Bioresources 10(4): 8461-8473.

20. TS EN310, 1999: Wood-based panels. Determination of modulus of elasticity in bending and of bending strength.

21. TS EN322, 1999: Wood-based panels. Determination of moisture content.

22. TS EN323, 1999: Wood-based panels. Determination of density.

23. Xu, W.T., Que, Z.L., 2016: Stress performance analysis of laminated veneer lumber (LVL) with holes and plywood reinforcement methods. China Forest Products Industry (11): 30-34.

24. Yildirim, M.N., Uysal, B., Ozcifci, A., Ertas, A.H., 2015: Determination of fatigue and static strength of scots pine and beech wood. Wood Research 60(4): 679-686.

25. Yoshihara, H., 2016: Analysis of the open-hole compressive streng th of spruce. Holzforschung 70(5): 449-455.

26. Zhou, J., Hu, C., Hu, S., Yun, H., Jiang, G., and Zhang, S., 2012: Effects of temperature on the bending performance of wood-based panels. BioResources 7(3): 3597-3606.

\author{
Nurdan Cetin Yerlikaya* \\ Yalova University \\ Faculty of Art And Design \\ Department of Interior Design \\ Central Campus, Cinarcik Road 77200 \\ YALOVA \\ TURKEY
}

Abdurrahman Karaman*

USAK UNIVERSITY

Banaz Vocational School

Department of Forestry

USAK

Turkey

*Corresponding authors: nurdan.yerlikaya@yalova edu.tr, abdurrahman.karaman@usak.edu.tr 